days both samples were sedimented and examined for auto. ágglutinability. No great difference was detected in the two samples. In general the red cells from the oxygenated blood became agglutinable a day or two before those in the sealed tube.

\section{The Effect of Heat.}

The non-specific and the specific agglutinins resemble each other in being thermostable. If sheep's serum capable of auto-agglutinating native washed red cells and of specifically agglutinating human red cells be subjected to a temperature of $56^{\circ} \mathrm{C}$. for half an hour it retains its capacity to agglutinate both kinds of red cells.

\section{The Removal of Agglutinins from Blood serum by Filtration through Porcelain.}

We have already seen that while agglítinogens are only. found in combination with the red cells, agglitinins, on the other liand, exist in the serum in the free state. If freshly drawn sheep's serum be filtered througli a porcelain carth filter candle under diminished atmospheric pressure, a pale clear fluid of low specific gravity is obtained free from specific and non-specific agglutinins. Such filtered serum lias no agglutinative action on fresh red cells whicl a control sample rapidly agglutinates, or on ald native red cells in which the control sample produces auto-agglutination. It is a point of interest that while filter eandles of : certain fineness of porosity btock the passage of all haemagglutinins, those of a slightly more porous character let some through. The size of the agglutinin aggregate would seem to correspond, therefore, to the diameter of the pores of a moderately fine filter candle. An attempt was made by using candles of different degrees of porosity to ascer tain whether any difference in filtrability - that is, in the size of the aggregrate-occurred between the non-specific and the specific form. As far as can be ascertained, how. ever, both seem to pass with equal readiness through candles of the same fineness of pore.

It may be that the excellence of filtered native serum as a medium for the formation of agglutinogen by red cells depends on the fact that filtered serum contains no haem. agglutinin, consequently the agglutinogen is not nentralized as soon as formed.

\section{Conclusion.}

The subject of auto-haemagglutination in disease will be considered in Part II. It is, however, desirable to sum up the conclusion established in regard to this (in vitro) part of the inquiry.

In the first place the phenomena of haemagglutination have been shown to possess a physiological as well as a biological significance. All red blood corpuscles ate capable of forming haemagglutinogen under certain conditions.

Agglutinogen, like agglutinin, exists in the non-specific form, agglutinogen $A$, and in a graded series of specific forms, agglutinogen $B, C, D$, etc. The specific and the non-specific agglutinogens (like the corresponding agglutinins) although allied, are not identical in composition or character.

Agglutinogen has so far only been found in combination with or attached to the surface or stroma of the red cells It apparently does not exist in the scrum in the free or uncombined state. The specific and non-specific agglutinins, on the other hand, are present in the serum in the free state, and both kinds are removed by filtering the serum through a porcelain filter.

THE Ministry of Pensions announces that officers and nurses who-have completed a course of sanatorium treatment and are certifled as likelr to benefit by a further course of treatment combined with training, will, if they decide to undergo such course, be granted retired pay at the rate appropiriate to 100 per cent. disablement during such curative training and for a period of six months after its termination. Further, the retired pay will be continued at a rate not less than that. for 50 per cent. disablement for two years theicafter. These special extensions will be conditional on the offieers presenting themselves for examination by the local tuberculosis officer from time to time as directed, and complying with any instrictions considercil necéssary for their treatment.

\section{SOME POINTS IN MIDWIFERY PRACTICE}

a Paper Read before the Cambridge Medcal

SocIetY.

$$
\text { BY }
$$

\section{W. J. YOUNG, L.R.C.P., M.R.C.S., PRESIDENT.}

THE doctor probably more than any man, and perhaps the accoucheur most of all, desires that the generation which succeeds him shall emulate his virtues, improve on his methods and avoid his errors, a sentiment expressed in the well-worn tag of the Sophoclean Ajax,

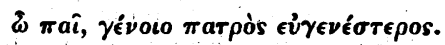

When we have become old enough to look back, when we have grown candid enough to admit, even to ourselves, our defects and our failures, we can still desire perfection: hence it seemed to me, since in this important branch of our profession so much can be done for the good of the patient, that a profitable discussion might well result from a paper on some points in midwifery practice.

\section{During Pregnancy.}

Taking the first of the three great natural divisions of our subject, we will look at a few matters in relation to pregnancy concerning which we are often called on to give advice-what to do and to avoid, and so forth. My custom is to tell the woman to lead a normal active life in all respects, -avoiding three things-shock, strain, and fatigue. I advise her also to turn a deaf ear to the counsels: of ald women of both sexes, and of certain books wliose chief characteristics seem to be sticky sentiment and sloppy moralizing.

In the absence of signs or symptoms, it is probably needless to trouble the prospective mother till the expiry of seven months, when external pelvimetry should be done and abdominal examination made to determine if there is likely to bo plenty of room for the head. If there seems any ground for feàr, the examination should be repeated every week and labuur induced if and when indicated. By this ineans we can avoid what may be fairly regarded as a discredit to our art-the bad forceps case with head at or above the brim. I fear that perhaps too many of us can look back on such cases with mingled feelings: The woman should also be instructed to report any departure from her normal health, and sy stematic repeated examinations of the urine should be made if there is previous history of renal or toxaemic trouble, or any sign that all is not well.

In preparation for the confinement, I think that the routine administration of quinine, gr. 1 twice $a$ day foi $a$ month before the event, with or without digitalis, acts as a good uterine tonic. I sball refer to this again.

I have always opposed, and I hope always to oppose, the practice of midivifery by midwives, sanctioned though it is by the hoariest antiquity, supported by widespread prejudice and ignorance, and backed by the Legislature. When we consider how much the riedical man can doand, indeed, ought to do-to talie his patient through her confinement expeditionsly, safely, with a minimum of pain, distress of mind, discomfort, and injury, we cannot view with indifference the denial of these advantages to so large a proportion c mother's. Tiue, onè sometimes hears a doctor say that he liates this branch of his work, and we all know how rery awkward its incidence can be, bat such things are not good arguments for the employment of midwives. What is wanted is doctors who love their worl.

A word on the thorny question of the induction of labour. My view is that this dernier ressort should not be postponed too long. : If the patient is wasted and wasting, if vomiting is severe and persistent in spits of treatment, if albuminuria and toxaemia are present, or eren an obscuie condition of marasmus, we onglit not to wait on and on in the liope for a living child when every day diminishes the mothier's chances. My mind goes back to such a case in which induction was postponed; the woman had a spontaneous labour at seven montlis, the child dying in thirty-six-hours, and the mother some hours later. Frankly, I am not in love with the diction of Pinard concerning the right of the fetus to its life. Hydrops amniti 
shoüld be watched literally from day to day, and relief. given before symptoms become too grave, if Nature does not forestall us.

For the vomiting of pregnancy I am old-fashioned enough to think lighly of iodine, of bismuth, and of ingluvin, but from what we were told at the last annual meeting of the British Medical Association, I suppose that one should resort early to treatment by psychotherapy for this condition.

\section{During Labour.}

As to the second division, labour itself, whilst it is true that meddlesome mid wifery is bad, the doctor who "never interferes, but leaves it all to Nature," may attend con. finements; he does not practise midwifery.

We all know but too well that the course of labour varies within extremely wide limits, even in the same woman at different times. Probably most of us can recall such cases as that of a quite young woman whose first labour gave her over three days of constant and severe pain, and of the woman of 36 whose big first baby was born after only one hour and a half. On the question of the influence of the age of the mother, my view-the outeome of the experience of myself and of others-is that in the great majority of cases of primiparae it makes extremely little difference, and that the talk in the books about "elderly primiparae - that is, over 30 ," is largely nonsense.

For irregular or fruitless pains in the first stage believe quinine bisulphate gr. vi in one dose to be useful, as is also chloral, and particularly morphine and scopolamine. This latter combination is a sheet anchor in those-trying cases of first stage in which the pains are very severe with "nothing doing" - the so-called "disturbed polarity" - which sometimes tend to go on for days wearing out the strength of the woman and the patience of the doctor. The dose, from $\frac{1}{4}$ to $\frac{1}{3} \mathrm{gr}$. of morphine, can be repeated as often as indicated, but it is very seldom that one need give more than two doses, generally in from four to eight hours after the first dose one finds the cervix dilated and the second stage progressing normally; not infrequently the child is born before the effects are passed off, much to the mother's gratification and to the credit of the accoucheur.

Whilst on this part of our subject I ought to say a word about twilight sleep-blessed phrase, worthy companion to "Mesopotamia" and "profound toxaemia"! I was fortunate in attending a discussion at March on this subject some time ago, the outcome of which was a general agreement that for the great bulk of cases it is neither necessary nor desirable; that its overloaded technique is either frivolous or puts it largely out of court for general practice; and that most, if not all, of its real benefits can be secured without the maintenance of the full state of amnesia. My own assurance to patients who ask me about twilight sleep is that they shall not be allowed to suffer unduly, a promise I do my best to fulfil; more than this no woman needs and no sensible woman wants.

Of complications of the first stage perhaps the chief in importance, from the point of view of discussion, is placenta praevia. Many years ago I stated my conviction, to which I still adhere, that in this formidable condition the interests of mother and child are so completely opposed that the soundest practice is to make no attempt to secure a living child unless the placenta is fairly well out of the way, the os dilated or easily dilatable, and the bleeding slight. Our procedure will largely depend on the condition of the os; if it dilates fairly readily to the fingers-and with all respect to the various bags and dilators, I still think that fingers were made before them-the best treatment is to separate the membranes and the placenta as far as one can reach with the finger, dilate up to four or five fingers, bring down a foot, pull the breech well down, give ergot or pituitary or nothing, and await-it is seldom or never long-the delivery. On the other hand, if the cervix is unyieldincr and the haenorrhage such as to cause anxiety, I believe that the proper treatment is Caesarean section. I think that resort to this operation as a routine treatment for the condition of placenta praevia is quite unjustified. Plugging the vagina for this complication I have never done, and do not think that I ever shall.

The course of the second stage and its treatment are to a great extent dominated by the presentation. It is said of Péan that he was so enamoured of his discovery of differential pereussion that he could percuss out a tapeworm in the small intestine; after reading about abdominal palpation I am quite willing to believe that some of those to whom the vagina is a via sacra are able to diagnose all presentations, even the most complex, yea, even to tell the sex of the child. But to most of us this Parnassus is unscalable; not infrequently also we have to confess failure with the classic two fingers. A story is told of a French professor who, demonstrating what he said was a face case, withdrew his finger from the mouth and held it up covered with meconium! All doubts about head presentations can be set at rest by introducing enough of the hand to find the ear and to determine exactly how it lies; the condition of the os can be investigated at the sane time, and the state of the pelvis. Not long ago I had an occipito-posterior case in which a hand, a foot, and the fuais were also presenting; I think that such a case might possibly tax the skill of the palpating expert. I do not wish to decry abdominal palpation, but only to suggest that it is not everything.

The occiput, in posterior presentations should invariably be rotated forwards unless Nature terminates the labour. speedily, and it should be a maxim with every accoucheur. never to put on forceps in these cases without first rotating; it makes all the difference.

Face cases at or above.the brim should be cither turned or rectified. For myself, I much prefer rectification, as then one knows exactly what there is to deal with. The great point in attempting rectification is first of all to rotate the occiput into the left inguinal region, if it is not already there; this manouvre, which I had the honour to use and to describe in 1911, is now included in the new edition of a leading textbool. With the anaestletized patient on her back across the bed, the ulnar horder of tho right fist pressing down the occiput and the left hand in the vagina pressing up the face, rectification is easily and speedily accomplished. Full flexion of the head can then be secured and the forceps applied.

With regard to version for other conditions than placenta praevia, if $I$ am in any doubt about the amount of room in the pelvis, I prefer to deal with the liead first rather than last, and $I$ do not regard podalic version as good practice in cases of small round pelvis.

It is, I think, much to be regretted that so many prac. titioners still use the ordinary forceps instead of the axis traction instrument. I have already remarked that the high fo"ceps case, particularly in primiparae, is a discredit to us which should be avoided by the induction of labour. directly it becomes difficult to press down the head into the pelvis. The funnel-shaped pelvis will, however, still lie in wait for us and sometimes cause very great difficulty in delivery, even to the death of the child. If it should so happen that we have to apply forceps at the brim, then we should make sure that the head is in the optimum position, adjust the forceps as accurately as possible to the sides of the head-the "lateral meridian" of the French school-make use of the advantage of Walcher's position, and pull in the axis of the pelvis. If, in spite of all our skill, we fail to deliver, the treatment is craniatomy; I consider Caesarean section in such cases improper practice.

I take for granted that chloroform is not spared when. ever indicated in labour. I always use the inhaler of Roth Drïger, which is again obtainable in this country. It ensures a supply of fresh air at every breath, the amount of chloroform is easily controlled, and the patient can hold the inhaler herself. A whiff of chloroform after the dose of scopolamine-morphine helps its action very materially:

No "point" in midwifery is of more vital concern or of more perennial interest than that of post-partum hasmorrhage, in which, for convenience, we may include bleeding in the third stage. We all know the many devices for dealing with this eneny, from compressing the aorta to pulling down and twisting the uterus with vulsella. But surely the b st treatment is to prevent it if possible, and I believe that much in this direction can be done by giving quinine and digitalis, and also calcium chloride or lactate, during the last month; it is also of the greatest importance that labour should not be allowed to drag on too. long in the second stage. I generally give an intramuscular injection of calcium chloride before delivery, and one. of pituitary extract directly the head is born; sugar also is probably very useful. One of my patients, who had nearly died in her twelfth and thirteenth labours, came 
quickly and safely through her fourteenth and fifteenth under treatment on these lines; labour was terminated by the forceps directly dilatation was sufficient, and ergot was given twenty minutes before delivery.

But, alas ! it has to be confessed that there seem to be bloods which fail to respond to the clotting influence of calcium, and uteri which laugh at pituitary and at ergot, and these will occasionally give us a crowded hour of mouth-drying anxiety. Fortunately, there is probably no uterine haemorrhage that cannot be controlled by bimanual compression, which cannot be arrested by the liot douche. One curious condition ought to be noted here, which I have observed several times. The uterus feels hard, and is obriously well contracted, and yet the bleeding goes on. Vaginal examination shows, however, that the lowest part of the uterus is still quite flabby, and sometimes distended with clot. If the placenta-has had some attachment to this area bleeding takes place, and the asual stimulants seem powerless to stop it; it censes at-onee under the hot douche.

I am still an obdurate sceptic, despite the eloquence of our Regius, in regard to the educational value of the M.B. thesis. If, however, we still must suffer such things, then I would modestly suggest the investigation of the reaction of different bloods or bloot groups to ealcium chloride, with a view to placing our clinical use of this sometimes potent agent on a sound and scientific basis, and to determining the proper dosage. To Dr. Grove is due the credit of introducing it for the treatment of haemorrhages, but I certainly think-his dose of 1 grain too small. I usually give 2 grains, dissolved - I keep the solution ready made-in 20 minims of 2 per cent. carbolic lotion. Another subject for investigation is the factors which in some cases seem to inhibit the action of pituitary extract on the uterus.

A further word about pituitary must be added before quitting this part of our subject. Practitioners of much greater experience than myself agree that it is one of ou most powerful weapons, terminating in a few minutes what would often otherwise be interminable cases in multiparae, and preventing or arresting haemorrlage. It acts at once or not at all, and $I$ do not believe the tales about it causing rupture of the uterus an hour after injection; the fact of rupture occurring then would to my mind prove that the rupture was not due to the drug. T'inere were brave men before Agamemnon, and there were ruptured uteri before pituitary extract. Of course, if a practitioner asks for trouble by giving it in obstructed labour he has only himself to thank, bit I decline to betieve that there is any risk at all in giving this drug to multiparae in cases where the head is in the pelvis and there is room for easy natural delivery.

Our third divi ion is concerned with puerperal condi. tions and their treatment. 'The aseptic accoucheur, if any such there be in actual existence, gowned and gloved and gas-masked, who shaves the vulva anä gives a bath of picric acid, will naturally douche the uterus in all cases and pursue a consonant post-operative routine; the ordinary general practitioner will, like Gallio, care for none of these things, and his patients will get along equally well. Cases of sepsis will occur, just as cases of embolism and white leg and mammitis and puerperal insanity, in which one will not be able to trace a cause, in which also there may have been no vaginal or other interference and no ascertainable history of exposure to infection. In view of this fact, the pursuit of a technique which experience has shown to be adequate is enough. As a last word on this I would like to ask two questions: "Ought retained membranes always to be removed at once, or may they be lefi a while?" also, "Should a torn cervix be sutured?"

Tro other deadly complications of the early puerperium may be mentioned. The first is reactionary, or late postpartum haemorrhage. A friend of mine died of it some years ago, and $I$ have had one narrow shave in my own practice. One stays with the patient a reasonable time, all seems well, and then after an bour or tro one is urgently summoned, to find the uterus full of clot, the woman blanched, bleeding, and in pain. Fortunately this trouble is rare, or our practice would be a nightmare.

'The other trouble is post-partum vomiting, of which I have had a fatal crse. I sappose that it must be due to some form of toxaemia where it is not hysterical. I certainly constitutes a very formidable complication, and is very refractory to treatment.
Though there of course remain a large number of points of great interest and importance, I think that I have gone on quite long enough, so will close without flourish or peroration.

\section{OBSERVATIONS ON CASLIS OF RICKETS IN AN OUT-PATIENT DEPARTMEN'T.}

$\mathbf{B Y}$

HELEN M. M. MACKAY, M.D.LoND., M.R.C.P., BEIT MEMORIÄL RESEARCH FETIOW ; ASSIBTANT PHYSICLAN, QUEEN'a
HOSPITAL FOR CHILPREN.

Ar the present time, in spite of the large amount of atten. tion which has been focussed upon the etiology of rickets, there appears to be no general agreement as to its cause. Mellanby believes that the ultimate factor determining the occurrence of rickets in puppies of a susceptible age is the absence in the diet of a sufficient quantity of "anti-rachitic factor" I-a substance which has been held to be identical with fat-soluble A. ${ }^{2}$ Yet Noël Paton and his co-workers, who, in the course of their investigations on rickets, have carried out somewhat similar experiments in dogs, con. sider that " some other factor than diet is the prime cause of rickets," " and that rickets " is directly correlated with overcrowding and confinement in insanitary houses." Hess, who, like most clinical workers, holds that riekets "is primarily a dietetic disorder," believes that cod-liver oil "is almost a specific" as a prophylactic or curative remedy, but at the same time holds that fat-soluble $A$ is only one among several factors concerned in the pathogenesis of rickets, ${ }^{5}$ and that probably "the danger to infants of a diet deficient in fat-soluble vitamine is slight, provided it includes sufficient calories and is otherwise complete." 6

Bull, commenting on his clinical and experimental investigations on rickets among foxhound puppies, concludes that "although the faulty nature of the food was closely associated with the production of the disease, it has been shown that it was not capable of producing the disease when other conditions were altered," and that rickets is probably "due to a reaction on the part of the organism to an infection or clironic intoxication." 7 Erdheim (working in Vienua during the time of shortage and of high prices, when very many among the population were under-nourished) examined pathologically a large number of caged rats which had spontaneously developed rickets at this time. He gives in his published report no particulars of the diet of these animals, but he shows a close relationship to exist between hypertrophic changes in the parathyroids and the presence of rachitic changes in the rats' bones-those rats having rickets had enlarged parathyroids with microscopic appearances indicative of hyperactivity of the glands. ${ }^{8}$ Erdheim also removed the parathyroids in rats, and bone changes similar to rickets followed this operation. This apparent contradiction he explains on the theory that the parathyroids in some way control calcium metabolism, and that in spontaneous rickets the hypertrophy indicates an effort at compensa. tion on the part of the organism. Erdheim's observations are of cousiderable interest, in view of the following facts: (a) The occurrence of a condition resembling tetany as a result of the experimental removal of the parathyroids; 9 (b) the extremely frequent association of tetauy with rickets and artificial feeding in clrildren; and $(c)$ the fact, as stated for instance by Holt, that in children " the active symptoms of tetany may be controlled by calcium," 10 the metabolism of which is disturbed in rickets. 'These facts would suggest that the hypertrophy of the parathyroids may, as Erdheim suggests, be a protective mensure against some common canse giving rise to abnormal calcium metabolism, to an increase of gnanidin in the blood, and in some way to both rickets and tetany.

Guanidin, a product of decomposition of protein, is, according to Noël Paton, the chemical substance which gives rise to the symptoms of tetany. ${ }^{11}$ Morpurgo ${ }^{12}$ isotated from the organs of white rats which suffered from a spontaneous ontbreals of osteomalacia in his laboratory a Gram-negative diplococcus, and succeeded in producing the disease in hundreds of other rats by subcutaneous inocalation of either the pure culture or the organs of animals containing the diphocoscus. When adult animals 